\title{
Pakchoi Antioxidant Improvement and Differential Rhizobacterial Community Composition under Organic Fertilization
}

\author{
Jianli Liao ${ }^{1}$, Jun Ye ${ }^{2} \mathbb{C}$, Yun Liang ${ }^{1}$, Muhammad Khalid ${ }^{1}$ and Danfeng Huang ${ }^{1, * \mathbb{C}}$ \\ 1 Key Laboratory of Urban Agriculture (South), Ministry of Agriculture, School of Agriculture and Biology, \\ Shanghai Jiao Tong University, Shanghai 200240, China; Jerry0427@sjtu.edu.cn (J.L.); \\ yunliangdoreen@gmail.com (Y.L.); kokub32@gmail.com (M.K.) \\ 2 Australian Centre for Ecogenomics, School of Chemistry and Molecular Biosciences, \\ University of Queensland, Brisbane, QLD 4072, Australia; j.ye@uq.edu.au \\ * Correspondence: hdf@sjtu.edu.cn; Tel.: +86-21-3420-6943
}

Received: 26 February 2019; Accepted: 21 March 2019; Published: 24 April 2019

\begin{abstract}
A high level of antioxidants in organic-produced vegetables has been attributed to soil conditions; however, little is known about the relationships between antioxidants and rhizobacteria under different fertilization treatments. A pot trial for pakchoi (Brassica campestris ssp. chinensis L.) was conducted under greenhouse conditions with: (1) control; (2) chemical fertilizer; and (3) organic fertilizer. The responses of the plant, soil properties, and rhizobacterial community were measured after 45 days of cultivation. Fertilization increased soil nutrient levels and pakchoi productivity and the reshaped rhizobacterial community structure, while no differences in rhizobacterial abundance and total diversity were observed. Generally, most plant antioxidants were negatively correlated with inorganic nitrogen ( $\mathrm{N}$ ) and positively correlated to organic $\mathrm{N}$ in soil. The genera of Arthrospira and Acutodesmus contained differential rhizobacteria under chemical fertilizer treatment, which are known as copiotrophs. In addition, the addition of a chemical fertilizer may stimulate organic substance turnover by the enrichment of organic compound degraders (e.g., Microbacterium and Chitinophaga) and the promotion of predicted functional pathways involved in energy metabolism. Several beneficial rhizobacteria were associated with organic fertilizer amended rhizosphere including the genera Bacillus, Mycobacterium, Actinomycetospora, and Frankia. Furthermore, Bacillus spp. were positively correlated with plant biomass and phenolic acid. Moreover, predictive functional profiles of the rhizobacterial community involved in amino acid metabolism and lipid metabolism were significantly increased under organic fertilization, which were positively correlated with plant antioxidant activity. Overall, our study suggests that the short-term application of chemical and organic fertilizers reshapes the rhizobacterial community structure, and such changes might contribute to the plant's performance.
\end{abstract}

Keywords: rhizobacteria; leafy vegetable; pakchoi; plant quality; pyrosequencing; organic fertilizer; mineral fertilizer

\section{Introduction}

Organic farming is regarded as an environmentally friendly cultivation method with the application of organic fertilizers, the biocontrol of pests and disease, crop rotation, and residue mulch in comparison to conventional farming. A recent meta-analysis indicates a higher level of antioxidants such as polyphenol, flavonoids, and antioxidases in organic agricultural products than in those derived from conventional farming [1]. In addition, a previous study demonstrates that the main difference in the protein profiles between plants under organic and conventional farming is attributed to the fertilization 
regime, rather than pest control treatments and rotation practices [2]. For the fertilization regime, phenolic compounds in root exudates of white lupin (Lupinus albus L. cv. Bac) are significantly decreased by the application of inorganic $\mathrm{N}$ [3]. A recent metabolomics study also suggests that increased inorganic $\mathrm{N}$ significantly decreases the antioxidants (i.e., peroxidases and superoxide dismutases) in the flag leaf of wheat and hinders $\mathrm{N}$ metabolism and secondary metabolism [4]. In contrast, the biosynthesis genes of flavonoids (i.e., chalcone synthase and isoflavone reductase) in alfalfa root are up-regulated under a N-limited condition [5]. Compared to mineral fertilizers, the application of organic fertilizers is shown to induce systematic resistance by increasing the antioxidant enzymes in cucumber [6]. We recently further demonstrated that the use of organic $\mathrm{N}$ (e.g., glycine) increased the levels of various antioxidants in lettuce when compared with the nitrate application [7]. These results suggest that the antioxidant level in plants might be influenced by the form and concentration of $\mathrm{N}$ in soil. However, most available studies focus on the effects of fertilizers on the physicochemical characteristics of plant and soil, and little is known about how the soil microbial properties respond to different fertilizations.

The bacterial community is the most dominant and diverse group in agricultural soils, and it plays a crucial role in organic matter degradation, nutrient processes, and disease suppression [8]. Thus, soil bacterial communities may further exert influences on plant growth and health [9]. Rhizobacteria are a group of bacteria that inhabit the soil surrounding roots with high microbial activities and their density is sustained by root exudates [10]. A recent study further demonstrates that long-term fertilization has a greater influence on rhizobacteria community compositions than plant root [11]. The significance of the interactions between rhizobacteria and roots in plant growth, nutrient uptake, disease, and insect resistance were observed by several authors [12,13]. These positive effects might be attributed to specific plant growth-promoting rhizobacteria (PGPR). Specifically, rhizobacteria can improve the plant resistance of biotic and abiotic stresses by regulating the production of antioxidants. For example, Bacillus and Pseudomonas are common PGPR with the ability to produce phytohormones and induce plant defense systems [14]. Pseudomonas spp. is also shown to mediate phenylpropanoid pathway of plants and further increase the phenolics and antioxidant enzymes production and antioxidants level [15]. Therefore, some PGPR have similar functions of organic $\mathrm{N}$ to improve plant antioxidants, which might be linked to the shifts in the rhizobacterial community by organic fertilization. However, little is known about the relationship between organic fertilizer associated rhizobacteria and plant antioxidants. In addition, most studies related to the responses of rhizobacterial community composition to organic fertilizer application focus on field crops such as wheat [16] and maize [17], and the fertilizer associated bacteria in the rhizosphere of leafy vegetables remain poorly understood.

Pyrosequencing is a powerful molecular approach that is used to detect microbial DNA and provide a whole microbial profile in environmental samples [18]. Compared to the traditional cultural method, pyrosequencing can provide savings in terms of labor and time [18,19]. Furthermore, 16S rRNA sequencing can be used to predict their functions by the phylogenetic investigation of communities by the reconstruction of unobserved states (PICRUSt) [20]. This efficient computation tool is used to explore bacterial functional signatures in diverse sources such as animal guts [21], water [22], and soil [23]. A previous study shows that the predicted functions of the biosynthesis of other secondary metabolites and the metabolism of terpenoids and polyketides of the rhizobacterial community are positively correlated to the leguminous biomass [24]. Thus, the functions of the rhizobacterial community might provide an ecological implication of the changed rhizosphere environment to plant growth.

In this study, we investigated how chemical fertilizers and organic fertilizers impact the plant, soil properties, and rhizobacterial community compositions. Pakchoi, a common short-term leafy vegetable with economic importance in China, was used as the model system. The rhizobacterial community was analyzed using $16 \mathrm{~S}$ rRNA gene amplicon sequencing. We hypothesized that the addition of different fertilizers would result in distinct antioxidant levels in pakchoi, and that rhizobacterial community compositions and functions would develop in response to respective fertilizers under short-term application. These analyses allowed us to obtain a better understanding of the relationships between 
rhizobacteria and plant performance under different fertilizations. These results may provide useful information for the selection of beneficial rhizobacteria for sustainable agricultural production.

\section{Materials and Methods}

\subsection{Soil and Material Preparation}

Soil from an organic vegetable farm $\left(30^{\circ} 51^{\prime} \mathrm{N}, 121^{\circ} 5^{\prime} \mathrm{E}\right)$ that was established in 2008 was sampled (0-20 cm sampling depth including the entire root zone) in March 2016. The soil was classified as a fluvisol according to the World Reference Base for Soil Resources [25]. The soil was air-dried, sieved through an 8-mm mesh, and then packed with woven bags in the lab before the pot trial. Analytical grade urea $\left(\mathrm{CO}\left(\mathrm{NH}_{2}\right)_{2}\right)$ and potassium dihydrogen phosphate $\left(\mathrm{KH}_{2} \mathrm{PO}_{4}\right)$ were used as the chemical fertilizer. Organic fertilizer produced from chicken manure and mushroom waste was provided by a suburban compost plant. The basic chemical properties of soil and organic fertilizer are provided in Table S1.

\subsection{Greenhouse Pot Trial}

A greenhouse pot trial was set up in September 2016 including the following three treatments: (1) control (CK) and no additions; (2) chemical fertilizer (CF); and (3) organic fertilizer (OF). The application rate of the chemical fertilizers applied was $0.6 \mathrm{~g} \mathrm{CO}\left(\mathrm{NH}_{2}\right)_{2}$ and $0.27 \mathrm{~g} \mathrm{KH}_{2} \mathrm{PO}_{4}$ per pot $\left(\mathrm{N} / \mathrm{P}_{2} \mathrm{O}_{5} / \mathrm{K}_{2} \mathrm{O}=0.28 / 0.14 / 0.13 \mathrm{~g} / \mathrm{pot}\right)$ [26]. Since the mineralization rate of compost or animal manure in soil ranges from $18 \%$ to $55 \%$ in the first year [27], organic farmers generally apply a relatively high amount of fertilizer to supply sufficient nutrients for plant growth when compared to conventional methods. To mimic a realistic application used in organic farming, the amount of organic fertilizer used here was $3.4 \% w / w(0.56-\mathrm{N} \mathrm{g} / \mathrm{pot})$, which is equal to twice the $\mathrm{N}$ of CF. Both fertilizers were applied as basal fertilizers. For each treatment, the soil and fertilizers were mixed thoroughly in a sterile Ziploc bag and then divided into 12 pots (top diameter $14 \mathrm{~cm}$, bottom diameter $10 \mathrm{~cm}$, and height $12 \mathrm{~cm}$, $700 \mathrm{~g} /$ pot).

The commercial variety of pakchoi (Brassica campestris ssp. chinensis L.) named "Xinxiaqing No. 6" was purchased from the ShouguangRenhe Seed Industry Co. Ltd. (Shandong, China). This variety has bright leaf ribs, dark green leaves, and a marked internode elongation compared to other relatives. Before sowing, $10 \mathrm{~g}$ of seeds were sterilized by $10 \%(w / v)$ peroxide solution for $30 \mathrm{~min}$ and then rinsed with sterilized distilled water. A portion of the sterilized seeds was cultivated on a 1/2 Murashige and Skoog-MS solid medium to ensure the completeness of sterilization. Afterwards, the sterilized seeds were germinated on wetted filter paper under an aseptic condition in the dark for two days. Three uniform seedlings were then transplanted to each pot. All pots were randomly arranged in the greenhouse, $5 \mathrm{~cm}$ apart, with controlled temperature $\left(16 \pm 1^{\circ} \mathrm{C}\right)$. Plants were grown without agricultural chemicals (e.g., pesticide or fungicide) and soil moisture was maintained at $60-70 \%$ water-holding capacity by adding tap water every $2-3$ days.

\subsection{Plant and Soil Sampling}

The vegetative growth of plants with 7-10 leaves was harvested during the optimal edible biomass and commodity stage at 45 days after transplanting. The bulk and rhizosphere soil were collected from each plant, respectively. The pakchoi plants and soil (i.e., bulk and rhizosphere soil) samples of four random pots per treatment were pooled and placed in labeled plastic bags on ice upon collection, respectively, resulting in three replicate pools to be used for further analysis. Physical and chemical analysis were conducted immediately after harvesting the plant samples. Bulk soil samples were air-dried, ground, and sieved through $2 \mathrm{~mm}$ mesh for chemical analysis. Rhizosphere soil, which is defined as the soil adhered tightly to roots, was sampled as previously described in [28] after gentle patting by sterile gloves, with slight modifications. Briefly, roots with rhizosphere soil were vortexed at maximum speed for $15 \mathrm{~s}$ in $25 \mathrm{~mL}$ phosphate buffer $\left(45.87 \mathrm{mM} \mathrm{NaH}{ }_{2} \mathrm{PO}_{4} \cdot \mathrm{H}_{2} \mathrm{O}, 61.57 \mathrm{mM}\right.$ 
$\mathrm{Na}_{2} \mathrm{HPO}_{4} \cdot 7 \mathrm{H}_{2} \mathrm{O}$, and $200 \mu \mathrm{L} / \mathrm{L}$ of Silwet L77). The mixture was passed through a $100 \mu \mathrm{m}$ nylon mesh filter to remove rocks and root debris. The filtrate was then centrifuged at $3200 \times g$ for $15 \mathrm{~min}$ to form a soil pellet. After discarding the supernatant, these rhizosphere soil samples were frozen in liquid nitrogen and stored at $-80^{\circ} \mathrm{C}$ for further molecular analysis.

\subsection{Analysis of Plant and Soil Properties}

The fresh weight and leaf number of pakchoi were recorded. Afterwards, the leaf area was measured by scanning the middle leaf of each plant using a Perfection V700 scanner (Epson, Bethesda, MD, USA) and processed by ImageJ (National Institutes of Health, Bethesda, MD, USA). The dry weight of the whole shoot was measured by drying at $60^{\circ} \mathrm{C}$ to a constant weight. Phenolic content, phenolic acid, flavonoids, and antioxidant activity were determined colorimetrically using a UV-Vis spectrophotometer (HITACHI U-2900, Tokyo, Japan) [29-32] and the details are provided in File S1.

Soil $\mathrm{pH}$ and electrical conductivity (EC) were measured by suspending dried soil in deionized water $(1: 5, w / v)$. An automated discrete analyzer (Smartchem, Frepillon, France) was used to analyze nitrate $\left(\mathrm{NO}_{3}{ }^{-}-\mathrm{N}\right)$ and ammonium $\left(\mathrm{NH}_{4}{ }^{+}-\mathrm{N}\right)$ in $2 \mathrm{M} \mathrm{KCl}$ soil extracts $(1: 10, w / v)$. Total inorganic $\mathrm{N}$ (TIN) was the sum of $\mathrm{NO}_{3}{ }^{-}-\mathrm{N}$ and $\mathrm{NH}_{4}{ }^{+}-\mathrm{N}$. Soil available phosphorus (AP) was analyzed in extracts with $0.5 \mathrm{M}$ sodium bicarbonate $(1: 20, w / v)$ using a spectrophotometric method. Total soil carbon (TC) and total soil nitrogen (TN) were determined by a Vario El III elemental analyzer (Elementar, Langenselbold, Germany). Total organic N (TON) was calculated as the difference between TN and TIN.

\subsection{Rhizobacterial Analysis}

Rhizosphere soil samples were subjected to total DNA extraction and sequencing of the 16S rRNA gene. Total DNA was extracted from the $0.5 \mathrm{~g}$ (wet weight) soil sample using the E.Z.N.A. Soil DNA Kit (Omega Bio-Tek, Norcross, GA, USA) according to the manufacturer's protocols. The purity and concentration of the DNA extracts $(1 \mu \mathrm{L})$ were analyzed using a NanoDrop 2000 fluorospectrometer (Thermo Fisher Scientific, Waltham, MA, USA). The 515F (5'-GTGCCAGCMGCCGCGG-3') and 907R (5'-CCGTCAATTCMTTTRAGTTT- $3^{\prime}$ ) primer sets were used for the amplification of the V4-V5 regions of the bacterial $16 \mathrm{~S}$ rRNA gene. Amplicons from each PCR sample were normalized to equimolar amounts and sequenced on an Illumina MiSeq sequencer (Illumina Inc., San Diego, CA, USA) at the Shanghai Personal Biotechnology Co. Ltd. (Shanghai, China). All raw sequences generated in this study were submitted to the Sequence Read Archive (SRA) database of the National Centre for Biotechnology Information and are accessible through accession number SRP148936.

Amplicon sequencing data were processed using fast length adjustment of short reads (FLASH) software (v1.2.7) [33] and the quantitative insights into the microbial ecology (QIIME, v1.8.0) pipeline. Briefly, only reads with an average Phred score higher than 20 and lengths over $150 \mathrm{bp}$, without ambiguous $\mathrm{N}$ bases and mismatched primers were considered for subsequent analysis. Trimmed sequences were assembled into contigs with the overlap regions longer than $10 \mathrm{bp}$ between the forward and reverse reads. The contigs were then clustered at a $97 \%$ sequence similarity for the operational taxonomic units (OTUs) by UCLUST [34]. A representative sequence was chosen from each OTU according to the default parameters. These sequences were used for OTU taxonomic classification by BLAST against the Greengenes database (Release 13.8). The OTUs accounting for less than $0.001 \%$ of all sequence data were removed. Bacterial $16 \mathrm{~S}$ rRNA marker genes were used to predict functional profiles by the PICRUSt tool, based on high-quality sequences [20].

\subsection{Statistical Analysis}

To reveal the overall effects of fertilization on the plant and bulk soil properties, we conducted both multivariate and univariate analyses. For the multivariate analysis, plant and edaphic variables were normalized to generate Euclidean distance matrices, respectively, and subjected to unconstrained principal coordinates analysis (PCoA). Permutational multivariate analysis of variance (PERMANOVA) was used to test the significant levels of fertilization. For the univariate analysis, Duncan's new 
multiple range test $(p<0.05)$ was performed. Pearson correlation analysis was applied to explore the relationships between the plant and soil parameters. It should be noted that data on plant growth parameters and antioxidants have been previously presented [35].

The rarefaction curve, Good's coverage, indices of richness (Chao1 and ACE, i.e., abundance-based coverage estimator) and diversity (Shannon and Simpson) were analyzed by QIIME and used to estimate the bacterial $\alpha$-diversity of each rhizosphere soil sample. Differences between these indices were analyzed using the Duncan test $(p<0.05)$. An unconstrained PCoA was carried out for a comparison of $\beta$-diversity rhizobacterial community using the Bray-Curtis similarity coefficient matrix generated from the rarefied OTU dataset. PERMANOVA based on this distance matrix was used to determine the effects of fertilization on rhizobacterial communities. Linear discriminate analysis effect size (LEfSe, LDA score > 2.7) was used to compare the rhizobacterial populations between different treatments [36]. The differential rhizobacteria were visualized by the ggpubr package in R (3.4.1) [37]. Furthermore, differences between predictive functional pathways were analyzed using the Duncan test $(p<0.05)$. As metabolism was the most abundant category of all functional profiles, we further conducted a Spearman correlation analysis between the functional pathways of metabolism and plant variables to illustrate the relationships between the functions of the rhizobacterial community and plant performance.

The unconstrained PCoA was performed by the vegan package in R (3.4.1), while the PERMANOVA was conducted with 999 permutations in PAST3 software [38]. Pearson, Spearman, and Duncan analyses were performed with Statistical Product and Service Solutions Software (SPSS, IBM, Chicago, IL, USA, version 22.0).

\section{Results}

\subsection{The Effects of Fertilizer on Plant and Soil Properties}

The plant and soil parameters of all three treatments were clearly clustered into groups after 45 days of pakchoi cultivation, with $95.96 \%$ and $99.16 \%$ of the variance components explained by the first two axes, respectively (Figure 1a,b). PERMANOVA analysis further indicated that the application of different fertilizers significantly influenced both the plant $(p=0.016)$ and edaphic $(p=0.004)$ properties (Table S2).

(a)

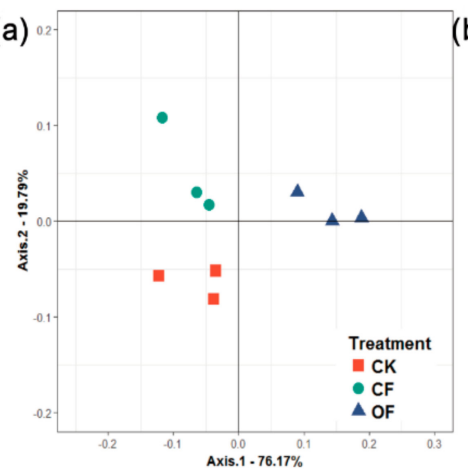

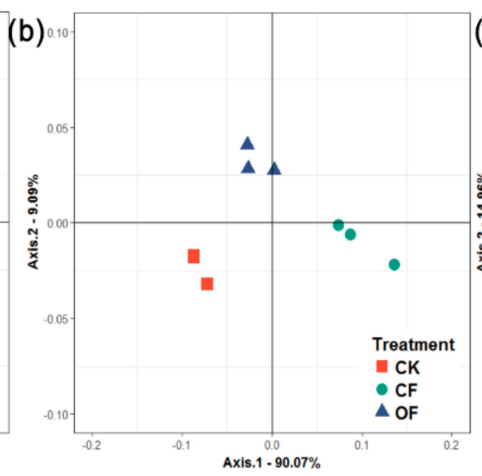

Figure 1. Unconstrained principal coordinates analysis ( $\mathrm{PCoA})$ illustrating the effect of fertilizers on the Euclidean distances of: (a) plant; (b) soil properties; and (c) the Bray-Curtis distance of rhizobacterial communities of pakchoi. $\mathrm{CK}$, control; $\mathrm{CF}$, chemical fertilizer; $\mathrm{OF}$, organic fertilizer.

Both chemical and organic fertilizers led to substantial increases in the yields of pakchoi compared to the control ( $53 \%$ and $67 \%$ dry weight, $p<0.05$, Table 1 ). However, there was no significant increase in the leaf number and leaf area for both CF and OF, as compared to CK. We further showed that pakchoi grown with organic fertilizer had the highest phenolic content (1.22 mg GAE/g FW), phenolic acid (145.71 mg CAE/g FW), and antioxidant activity (1.38 mM Trolox/g FW) among all treatments $(p<0.05$, 
Table 1). In contrast, the addition of the chemical fertilizer significantly decreased the phenolic content, flavonoids, and antioxidant activity by $23 \%, 36 \%$, and $24 \%$ when compared to the CK treatment.

Table 1. The soil and plant variables under different fertilizations.

\begin{tabular}{|c|c|c|c|}
\hline Parameter & CK & $\mathrm{CF}$ & OF \\
\hline \multicolumn{4}{|l|}{ Plant } \\
\hline Fresh weight (g) & $2.10 \pm 0.20 b$ & $4.11 \pm 1.66 \mathrm{a}$ & $3.84 \pm 1.05 \mathrm{a}$ \\
\hline Dried weight (g) & $0.15 \pm 0.02 b$ & $0.23 \pm 0.02 \mathrm{a}$ & $0.25 \pm 0.05 \mathrm{a}$ \\
\hline Leaf number & $7.67 \pm 0.58 a$ & $9.00 \pm 1.00 \mathrm{a}$ & $9.00 \pm 1.00 \mathrm{a}$ \\
\hline Leaf area $\left(\mathrm{cm}^{2}\right)$ & $13.78 \pm 2.05 \mathrm{a}$ & $16.75 \pm 1.25 \mathrm{a}$ & $15.63 \pm 4.93 \mathrm{a}$ \\
\hline Phenolic content (mg GAE/g FW) & $0.88 \pm 0.03 b$ & $0.68 \pm 0.08 c$ & $1.22 \pm 0.06 \mathrm{a}$ \\
\hline Phenolic acid (mg CAE/g FW) & $52.72 \pm 8.28 b$ & $53.08 \pm 7.92 b$ & $145.71 \pm 12.80 \mathrm{a}$ \\
\hline Flavonoids (mg QE/g FW) & $18.40 \pm 2.53 \mathrm{a}$ & $11.78 \pm 2.45 b$ & $18.17 \pm 1.12 \mathrm{a}$ \\
\hline $\begin{array}{l}\text { Antioxidant activity (mM Trolox/g } \\
\text { FW) }\end{array}$ & $1.13 \pm 0.06 b$ & $0.86 \pm 0.12 \mathrm{c}$ & $1.38 \pm 0.05 \mathrm{a}$ \\
\hline \multicolumn{4}{|l|}{ Soil } \\
\hline $\mathrm{pH}$ & $8.02 \pm 0.03 b$ & $8.01 \pm 0.01 b$ & $8.07 \pm 0.01 \mathrm{a}$ \\
\hline $\mathrm{EC}(\mu \mathrm{S} / \mathrm{cm})$ & $223.00 \pm 6.24 b$ & $465.33 \pm 31.82 \mathrm{a}$ & $432.00 \pm 8.19 \mathrm{a}$ \\
\hline Available P (mg/kg) & $107.18 \pm 10.77 b$ & $164.18 \pm 5.84 \mathrm{a}$ & $180.57 \pm 10.51 \mathrm{a}$ \\
\hline Total C (\%) & $2.05 \pm 0.07 b$ & $2.19 \pm 0.08 b$ & $2.44 \pm 0.13 \mathrm{a}$ \\
\hline Total N (\%) & $0.22 \pm 0.00 c$ & $0.24 \pm 0.01 b$ & $0.27 \pm 0.01 \mathrm{a}$ \\
\hline $\mathrm{NH}_{4}{ }^{+}-\mathrm{N}(\mathrm{mg} / \mathrm{kg})$ & $12.61 \pm 1.10 \mathrm{a}$ & $10.47 \pm 0.26 b$ & $4.81 \pm 0.60 \mathrm{c}$ \\
\hline $\mathrm{NO}_{3}{ }^{-}-\mathrm{N}(\mathrm{mg} / \mathrm{kg})$ & $14.37 \pm 4.29 b$ & $111.09 \pm 32.89 \mathrm{a}$ & $39.11 \pm 8.46 b$ \\
\hline $\mathrm{TIN}(\mathrm{mg} / \mathrm{kg})$ & $26.98 \pm 3.77 b$ & $121.56 \pm 33.00 \mathrm{a}$ & $43.92 \pm 8.23 b$ \\
\hline TON $(\%)$ & $0.21 \pm 0.00 \mathrm{~b}$ & $0.23 \pm 0.00 \mathrm{~b}$ & $0.27 \pm 0.01 \mathrm{a}$ \\
\hline $\mathrm{C} / \mathrm{N}$ ratio & $9.55 \pm 0.15 a$ & $9.03 \pm 0.13 b$ & $8.92 \pm 0.35 b$ \\
\hline
\end{tabular}

Data are presented as the means \pm standard deviation. Data followed by different letters are statistically significant differences $(p<0.05)$ according to Duncan's test $(n=3)$. CK, control; $C F$, chemical fertilizer; $O F$, organic fertilizer; $\mathrm{GAE}$, garlic acid equivalent; FW, fresh weight; $\mathrm{CAE}$, caffeic acid equivalent; $\mathrm{QE}$, quercetin equivalent; $\mathrm{EC}$, electronic conductivity; TIN, total inorganic N; TON, total organic N.

For the edaphic parameters, soil $\mathrm{pH}$ increased from 8.0 to 8.1 , on average, with the application of the organic fertilizer; however, there was no detectable change in soil pH between CF and CK (Table 1). As expected, fertilization significantly increased the level of EC, AP, and TN in the soil. Specifically, the chemical and organic fertilizers both significantly elevated the soil EC when compared to the control. The levels of $\mathrm{NH}_{4}{ }^{+}-\mathrm{N}$ content in the $\mathrm{CF}$ and $\mathrm{OF}$ was $17 \%$ and $62 \%$ lower than that of $\mathrm{CK}$, respectively. In contrast, soil $\mathrm{NO}_{3}{ }^{-}-\mathrm{N}$ content and TIN were significantly increased by $673 \%$ and $351 \%$, respectively, when CF was compared to the control and no difference was observed between $\mathrm{OF}$ and CK. The increased TON was only observed in the organic fertilizer treatment, while the $\mathrm{C} / \mathrm{N}$ ratio was significantly decreased after the fertilization.

\subsection{Correlations between Plant and Soil Properties}

To define how soil properties may contribute to plant performance, we conducted Pearson correlation analysis between the plant and soil variables. Plant dry weight was positively correlated to nutrient-related soil properties (i.e., EC, $\mathrm{AP}, \mathrm{TN}$, and TON) and negatively correlated to $\mathrm{NH}_{4}{ }^{+}-\mathrm{N}$ content and $\mathrm{C} / \mathrm{N}$ ratio $(p<0.05$, Table 2$)$. In general, the measured antioxidants in this study were positively correlated to soil $\mathrm{pH}, \mathrm{TC}, \mathrm{TN}$, and $\mathrm{TON}$ and negatively correlated to inorganic $\mathrm{N}$ (i.e., $\mathrm{NH}_{4}{ }^{+}-\mathrm{N}, \mathrm{NO}_{3}{ }^{-}-\mathrm{N}$, and TIN). Notably, positive correlations between antioxidant activity and all of the other antioxidants in plants were observed ( $p<0.05$, Table S3), indicating that this parameter represents the overall performance of plant antioxidants. 
Table 2. Pearson correlation between soil and plant variables.

\begin{tabular}{|c|c|c|c|c|c|c|c|c|}
\hline Parameter & $\begin{array}{c}\text { Leaf } \\
\text { Number }\end{array}$ & $\begin{array}{l}\text { Leaf } \\
\text { Area }\end{array}$ & $\begin{array}{c}\text { Fresh } \\
\text { Weight }\end{array}$ & $\begin{array}{c}\text { Dry } \\
\text { Weight }\end{array}$ & $\begin{array}{l}\text { Phenolic } \\
\text { Content }\end{array}$ & $\begin{array}{c}\text { Phenolic } \\
\text { Acid }\end{array}$ & Flavonoids & $\begin{array}{c}\text { Antioxidant } \\
\text { Activity }\end{array}$ \\
\hline $\mathrm{pH}$ & 0.154 & -0.105 & 0.250 & 0.533 & 0.774 * & $0.853 * *$ & 0.359 & 0.618 \\
\hline EC & 0.651 & 0.349 & 0.654 & 0.786 * & 0.010 & 0.393 & -0.512 & -0.161 \\
\hline Available P & 0.617 & 0.257 & 0.582 & 0.779 * & 0.343 & 0.645 & -0.300 & 0.190 \\
\hline Total C & 0.235 & 0.190 & 0.399 & 0.482 & 0.615 & $0.825^{* *}$ & 0.281 & 0.527 \\
\hline Total N & 0.486 & 0.072 & 0.431 & $0.717^{*}$ & 0.600 & $0.840 * *$ & 0.024 & 0.472 \\
\hline $\mathrm{NH}_{4}{ }^{+}-\mathrm{N}$ & -0.457 & -0.260 & -0.458 & $-0.722 *$ & $-0.765 *$ & $-0.928^{* *}$ & -0.213 & -0.630 \\
\hline $\mathrm{NO}_{3}{ }^{-}-\mathrm{N}$ & 0.391 & 0.386 & 0.517 & 0.359 & -0.601 & -0.243 & -0.698 * & -0.665 \\
\hline TIN & 0.355 & 0.365 & 0.481 & 0.303 & -0.657 & -0.312 & $-0.712 *$ & $-0.710 *$ \\
\hline TON & 0.426 & 0.008 & 0.349 & 0.669 * & $0.722 *$ & $0.903 * *$ & 0.151 & 0.603 \\
\hline $\mathrm{C} / \mathrm{N}$ ratio & $-0.746^{*}$ & 0.029 & -0.374 & $-0.878^{* *}$ & -0.300 & -0.549 & 0.426 & -0.090 \\
\hline
\end{tabular}

Correlation significant levels: ${ }^{*} p<0.05$ level, ${ }^{* *} p<0.01$. Significant correlations were showed in bold.

\subsection{Rhizobacterial Community Composition}

Fertilization had significant effects on the soil properties and plant performance. We hypothesized that these shifts might be linked to changes of rhizobacterial community resulting from fertilization and therefore analyzed the composition of the bacterial communities in rhizosphere soil. A total of 368,905 16S rRNA sequences were obtained from nine samples covering three replicates for each of the three treatments, which clustered into 7539 OTUs with the number of OTUs ranging from 2984 to 3645 per sample (Table S4). The rarefaction curves showed that the observed species likely reached the plateau phase (Figure S1), with the Good's coverage estimate fluctuating between 0.90 and 0.91, suggesting that the generated dataset was sufficient for further analysis.

The addition of different fertilizers had no significant effects on the bacterial richness (Chao1 and ACE) and diversity (Shannon and Simpson) indices in the rhizosphere of pakchoi. However, unconstrained PCoA illustrated that the composition of the rhizobacterial communities was clearly separated based on the fertilizer treatments along the first axis (Figure 1c). PERMANOVA analysis further showed that fertilization had a significant effect on the bacterial community in rhizosphere soil $(p=0.005$, Table S2).

A total of 35 bacterial phyla and two archaeal phyla were assigned among all of the rhizosphere soil samples. Proteobacteria (43.56\% in average) was the most abundant bacterial phylum (Figure S2), followed by Actinobacteria (10.37\%), Acidobacteria (8.69\%), and Chloroflexi (7.94\%).

\subsection{Fertilizer-Associated Rhizobacteria}

Given the clear separation of rhizobacterial communities between treatments, we then explored which specific microbial taxa were present and responsive in each treatment using LEfSe analysis (Figure 2). In the rhizosphere amended with organic fertilizer, we observed that the phylum Firmicutes was significantly higher than the other treatments, particularly for OTUs from the family Planococcaceae and the genera Bacillus and Halakalibacillus. In addition, OTUs from two families of Hyphomicrobiaceae (Proteobacteria) and Cytophagaceae (Bacteroidetes) and three genera belonged to the phyla Actinobacteria (Mycobacterium, Actinoycetospora, and Frankia) were enriched in OF. In contrast, the relative abundance of OTUs from the genera Microbacterium (Actinobacteria), Arthrospira (Proteobacteria), Sphingopyxis (Proteobacteria), Acutodesmus (Cyanobacteria), Chitinophaga (Bacteroidetes), and the family Parachlamydiaceae (Chlamydiae) exhibited significant increases with the addition of chemical fertilizer. OTUs from Carnobacterium (Firmicutes) and Aquincola (Proteobacteria) were responsible for the difference in the rhizosphere environment of CK. 


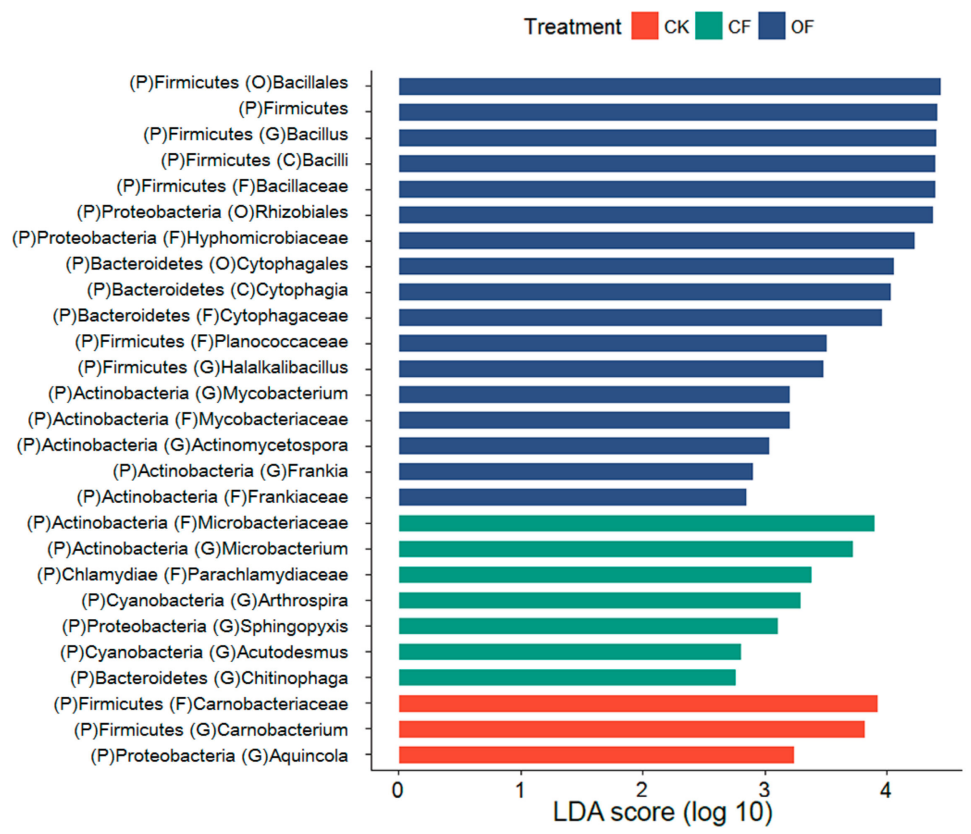

Figure 2. LEfSe analysis of differentially rhizobacteria among different fertilizations. $\mathrm{CK}$, control; $\mathrm{CF}$, chemical fertilizer; $\mathrm{OF}$, organic fertilizer; $(\mathrm{P})$, phylum; $(\mathrm{C})$, class; $(\mathrm{O})$, order; $(\mathrm{F})$, family; $(\mathrm{G})$, genus.

\subsection{Correlations between Plant Parameters and Rhizobacteria}

We further performed Spearman correlation analysis to examine the relationships between the rhizobacterial community and the changes in plant variables. The correlations between the most abundant 40 genera (Table S5) and plant variables among all treatments are shown in Figure 3. In the rhizobacterial community, most genera affiliated to the phyla Proteobacteria and Actinobacteria were significantly correlated to plant biomass (i.e., fresh weight or dry weight, $p<0.05$ ). Additionally, several OTUs were negatively correlated to different parameters of antioxidants in pakchoi $(p<0.05)$. For example, the relative abundance of Plesiocystis (Proteobacteria) was negatively correlated to phenolic acid $\left(R^{2}=-0.717, p=0.030\right)$ while Opitutus (Verrucomicrobia) was negatively correlated to flavonoids $\left(R^{2}=-0.750, p=0.020\right)$. There were negative correlations for Flavisolibacter (Bacteroidetes) in relation to plant phenolic content and phenolic acid $\left(R^{2}=-0.667, p=0.049\right.$ and $R^{2}=-0.750$, $p=0.020$, respectively). Additionally, significant negative correlations were observed between the genus Raphanus (Proteobacteria) and plant phenolic content and antioxidant activity $\left(R^{2}=-0.767\right.$, $p=0.016$ and $R^{2}=-0.733, p=0.025$, respectively). In contrast, we found that the genera Rhodoplanes (Proteobacteria) and Solirubrobacter (Actinobacteria) were positively correlated to antioxidant activity $\left(R^{2}=-0.800, p=0.010\right.$ and $\left.R^{2}=0.700, p=0.036\right)$. There were positive correlations between plant phenolic acid and the genera Bacillus (Firmicutes) and Planctomyces (Planctomycetes) $\left(R^{2}=0.683\right.$, $p=0.042$ and $R^{2}=0.667, p=0.049$, respectively), which were the only two genera that were significantly correlated to both plant biomass and antioxidants (i.e., phenolic acid). 


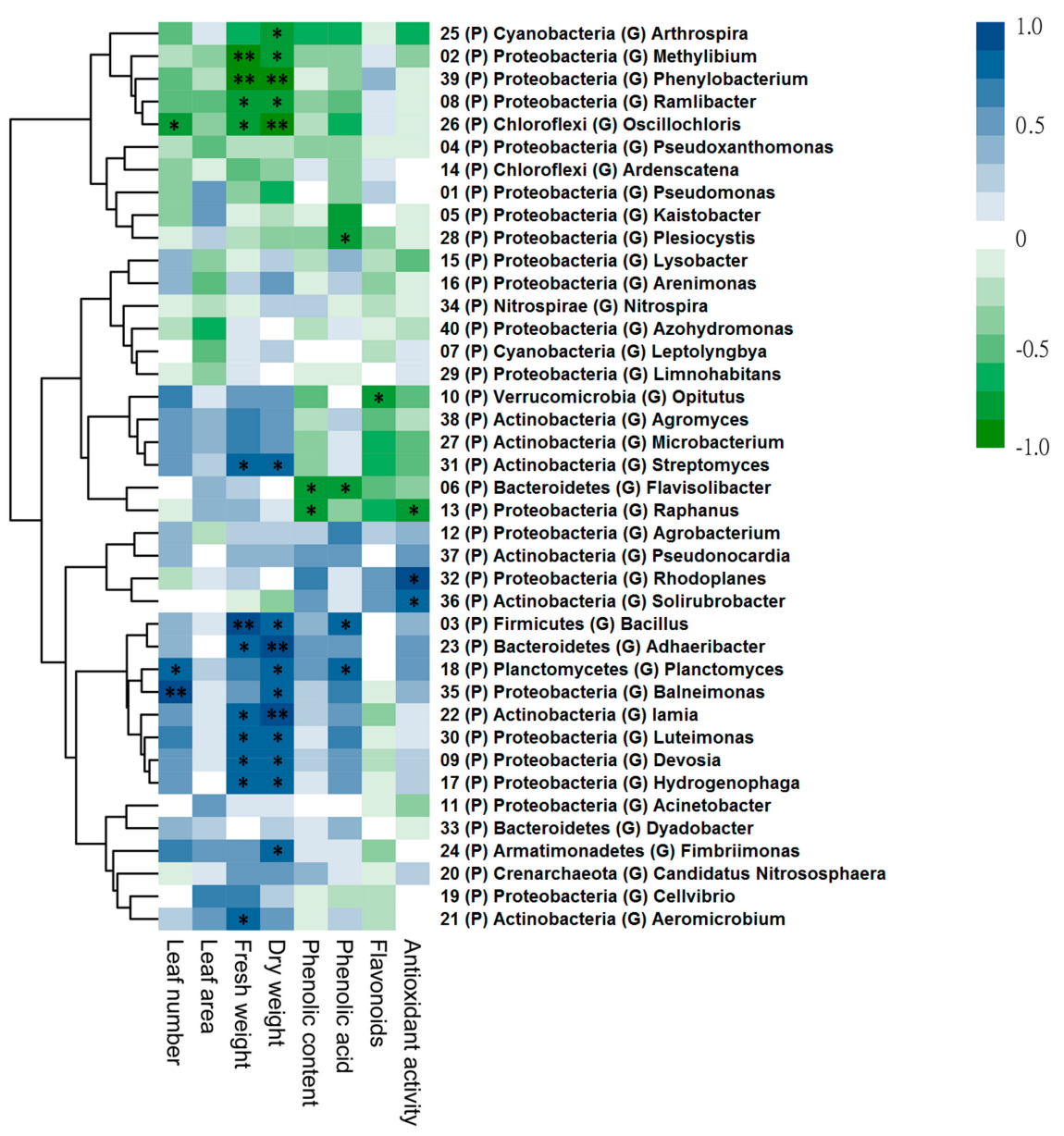

Figure 3. Spearman correlation between plant properties and the 40 most abundant genera in the rhizosphere presented by heatmap. The number in front of the bacteria represent the rank of relative abundance on average. Significance levels: *: $p<0.05 ;{ }^{* *}: p<0.01$. (P), phylum; $(\mathrm{G})$, genus.

\subsection{Correlation between the Predicted Functional Metabolism Profiles and Plant Traits}

Given that changes of microbial communities are generally associated with shifts in microbial functions that might influence plant performance, we predicted the functions of rhizobacterial community by PICRUSt and conducted a Spearman correlation analysis between predictive microbial functions and plant productivity and quality (i.e., dry weight and antioxidant activity). The PICRUSt results indicated that metabolism was the most dominant functional pathway and ranged from $50.12 \%$ to $50.89 \%$ of all functional profiles under different fertilizations (Figure S3). In level 2 metabolic pathways, amino acid metabolism (10.65\% on average), carbohydrate metabolism $(9.92 \%)$, and energy metabolism $(5.92 \%)$ were the most abundant pathways in the functional profile (Figure 4$)$. In addition, amino acid metabolism and lipid metabolism were significantly increased by adding organic fertilizer, while energy metabolism and the metabolism of cofactors and vitamins were stimulated by chemical fertilizer $(p<0.05)$. Furthermore, xenobiotic biodegradation and metabolism in CF was significantly lower than CK $(p<0.05)$. The results of the Spearman correlation analysis suggested that plant dry weight was positively correlated to most functional pathways assigned in metabolism and negatively correlated to xenobiotic biodegradation and metabolism $\left(R^{2}=-0.728, p=0.026\right)$. In addition, plant antioxidant activity was strongly correlated to amino acid metabolism $\left(R^{2}=0.733, p=0.025\right)$, lipid metabolism $\left(R^{2}=-0.833, p=0.005\right)$, and metabolism of other amino acids $\left(R^{2}=0.717, p=0.030\right)$. 


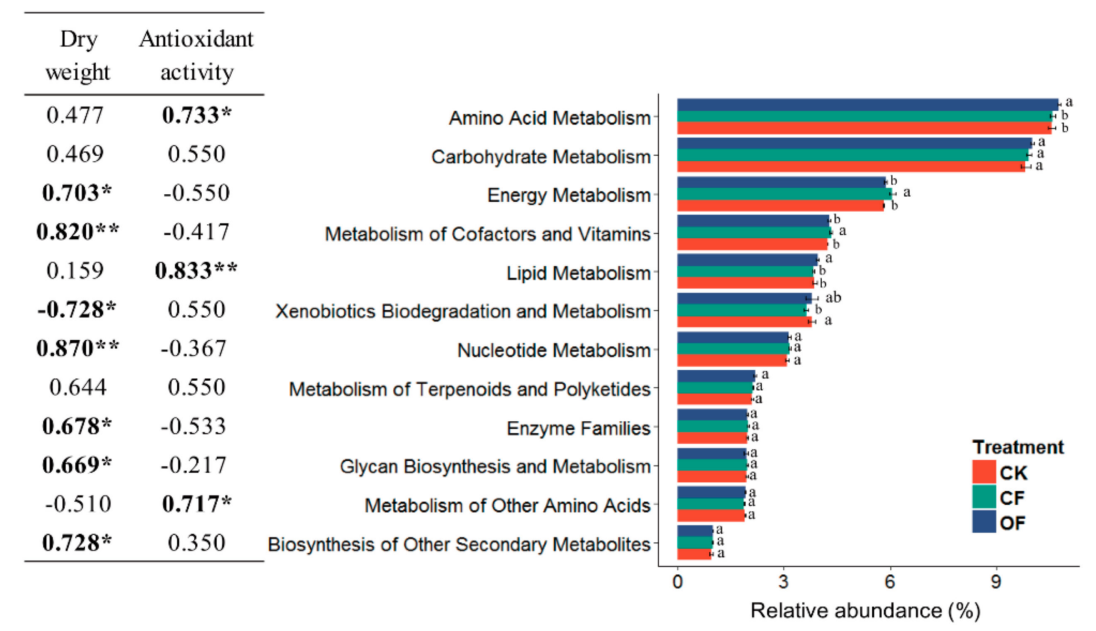

Figure 4. Predictive metabolic level 2 functions of rhizobacterial communities under different fertilizations. Bars with different letters are significantly different ( $p<0.05$, Duncan's test). The table shows the Spearman correlation coefficients between the predictive functions and plant dry weight and antioxidant activity. Significance levels: *: $p<0.05 ;{ }^{* *}: p<0.01$.

\section{Discussion}

This study aimed to explore the association of the rhizobacterial community composition with chemical and organic fertilizers and the potential rhizobacteria that may influence plant growth and biosynthesis of antioxidants. Overall, our results show that plant performance, soil properties, and rhizobacterial community composition were significantly influenced by fertilization (Figure 1 and Table S2). Chemical and organic fertilizations increased soil nutrient levels and plant yields consistently but presented distinct levels of antioxidants in the shoot of pakchoi (Table 1). Subsequently, we observed specific rhizobacteria enriched in different fertilized soils that might be related to the regulation of plant growth and the biosynthesis of antioxidants (Figures 2 and 3). Moreover, diverse functional pathways involved in the metabolism of the rhizobacterial community had significant correlations with plant productivity and antioxidant activity.

\subsection{The Impact of Fertilizers on Soil and Plant Properties and Rhizobacterial Community}

Our results show that organic fertilization produced a high quality of pakchoi in terms of the antioxidant properties measured in this study when compared to chemical fertilization (Table 1). Most antioxidant measures (i.e., phenolic content, phenolic acid, and flavonoids) were negatively correlated to inorganic $\mathrm{N}\left(\mathrm{NO}_{3}{ }^{-}-\mathrm{N}\right.$ and/or $\left.\mathrm{NH}_{4}{ }^{+}-\mathrm{N}\right)$ in the soils (Table 2). This concurs with our metabolic study that showed that $\mathrm{NO}_{3}{ }^{-}-\mathrm{N}$ as the $\mathrm{N}$ source hindered the accumulation of diverse intermediates involved in the phenylpropanoid and flavonoid pathways in lettuce and led to low antioxidant activity when compared to organic N (e.g., glycine) [7]. Similarly, this reasoning could be applied for the positive correlations between phenolic acid in plants, and TN and TON in soil (Table 2), which could be attributed to the increase of dissolved organic $\mathrm{N}$ content under a high TON condition [39], particularly low molecular weight organic $\mathrm{N}$ (e.g., amino acids and peptides) that can be used by the plant directly [40]. Hence, the antioxidants in plants could be regulated by the form and amount of $\mathrm{N}$ in soil changed by fertilization.

Given the introduction of a large amount of organic matter and exotic microorganisms [41] as well as the improvement of soil aggregation, aeration, and nutrient content by organic fertilizer, organic fertilizer amendment generally increases the bacterial abundance and diversity in bulk soil and rhizosphere, whereas chemical fertilizer has the opposite trend under a long-term condition [16]. However, this phenomenon was not found in our study, which might be due to the direct effect of soil resilience on short-term fertilization. Specifically, soil microorganisms have been shown to form a more 
stable community under the same long-term cultivation practice (e.g., organic fertilizer application and vegetable production) and thus tend to recover to be more similar to their original condition after disturbance [42]. Thus, it is likely that no difference in the rhizobacterial abundance and diversity of pakchoi under different fertilization is partially responsible for the long-term organically managed soil we used here.

Fertilization had a substantial impact on the composition of the rhizobacterial community of pakchoi (Figure 1c and Table S2). Although most studies indicate that the root exudates are the main driver in shaping the compositions of the bacterial community in the rhizosphere [10], recent studies show that the fertilizer regime could be a more important factor than plant exudation in alerting the rhizobacterial community structures of diverse field crops [11]. We further observed several fertilizer-associated microbial taxa in the rhizosphere of pakchoi. Some of their ecological signatures were consistent with the features of fertilizers. For example, members belonging to the genera Halalkalibacillus (Firmicutes) and Sphingopyxis (Proteobacteria) are known as halophilic bacteria $[43,44]$ and were associated with $\mathrm{OF}$ and CF, respectively. This may reflect a more saline environment of the rhizosphere amended with fertilizers than the control. In addition, Arthrospira spp. assigned to the order Oscillatoriales are reported to increase in water with high $\mathrm{N}$ content [45] while Acutodesmus spp. are known as copiotrophs [46], indicating that mineral fertilizer addition appears to stimulate the growth of copiotrophic taxa in the rhizosphere and this observation is in line with another study [16]. Interestingly, we also observed that organic fertilizer enriched several rhizobacteria with the abilities in plant growth promotion (Figure 2). For example, members belonging to the genera Mycobacterium, Actinomycetospora, and Frankia (Actinobacteria) and the genus Bacillus (Firmicutes), which have been shown to benefit plants, were highly associated with OF. Specifically, Mycobacterium spp. and Actinomycetospora spp. are reported to produce indole-3-acetic acid [13] and antibiotics [47], respectively. Frankia spp. are Gram-positive bacteria and recognized as diazotrophs [13]. OTUs from the genus Bacillus are reported as well-known PGPRs that could improve plant growth and resistance of diverse environmental stresses [14]. In addition, some chemical fertilizer-associated rhizobacteria could be related to the degradation of organic substances such as the genera Microbacterium (Actinobacteria) and Chitinophaga (Bacteroidetes) [14,48].

When focusing the analysis on the predicted metabolic functions of the rhizobacterial community, we found that a range of functional pathways were promoted by fertilization, suggesting that the addition of an organic or chemical fertilizer stimulated specific groups of bacteria in the respective rhizosphere. The organic $\mathrm{N}$ and lipids provided by the organic fertilizer could be observed by PICRUSt analysis, which showed greater amino acid and lipid metabolism of the rhizobacterial community in OF than CF (Figure 4). In addition, our recent work on soil nutrient processes with different $\mathrm{C} / \mathrm{N}$ ratio fertilizers indicates that the addition of the chemical fertilizer significantly increases $\mathrm{CO}_{2}$ and $\mathrm{N}_{2} \mathrm{O}$ emissions in the soil when compared to the control [49]. This could be supported in this study where the pathways of the rhizobacterial community involved in energy metabolism including $\mathrm{C}$ and $\mathrm{N}$ metabolism were stimulated by the chemical fertilizer (Figure 4), suggesting that mineral fertilization could accelerate organic substance turnover [50] by changing the composition of the rhizobacterial community.

Together, these results show that the shifted predicted functional pathways in the rhizosphere amended with the chemical fertilizer may lead to an acceleration of the organic substance degradation in the soil $[49,50]$. Organic fertilizer application increased the abundance of rhizobacteria related to the improvement of plant growth and health, which was consistent with our previous work [48]. The shift of the rhizobacterial community composition amended with organic fertilizer may provide a better rhizosphere ecosystem for the growth of pakchoi, which could be linked to the improvement of plant productivity and quality. 


\subsection{Links between Rhizobacteria and Plant Performance}

We next used the Spearman correlation analysis to describe the relationships between plant performance and rhizobacteria (Figures 3 and 4). Several rhizobacteria or their metabolic functions were significantly correlated to plant traits. For example, we observed that Bacillus spp., which were organic fertilizer associated rhizobacteria (Figure 2), were positively correlated to plant biomass and phenolic acid (Figure 3). This phenomenon is supported by numerous studies that have reported that Bacillus spp. are able to improve plant performance by producing antibiotics or inducing the expression of defense-related genes in plants $[14,51]$. In addition, a group of rhizobacteria involved in nutrient transformation were significantly correlated to plant performance. For example, the genera Hydrogenophaga, Balneimonas, Luteimonas, and Planctomyces were positively correlated to plant biomass. Hydrogenophaga spp. is identified as a key player in promoting the nutrient cycle in the paddy topsoil [52], while members belonging to the other genera can enhance the phosphorus availability in soils [53-55]. These observations can be partially supported by the predicted functions analysis that most functions related to nutrient processes (i.e., energy metabolism, cofactor and vitamin metabolism, nucleotide metabolism, and enzyme family) have positive correlations with plant yield (Figure 4). Consistently, a recent study reports that the shifted microbial functions by fertilization might contribute to soil nutrient turnover and thus affect rice productivity [56]. It is worth noting that positive correlations were found between plant antioxidant activity and increased metabolic functions by organic fertilizer amendment (i.e., amino acid metabolism, lipid metabolism, and metabolism of other amino acids). These results imply that functional prediction analysis could reflect the rhizosphere environment, showing that increased antioxidant activity in plants might be related to a high amino acid condition [7]. Although the distinct responses of plant performance were primarily caused by the incorporation of chemical and organic fertilizers, respectively, we propose that the shift in rhizobacterial community composition might also play important roles in mediating plant growth and health. However, the functions of rhizobacteria in plant traits should be further investigated under soils with the same nutrient conditions. Overall, an understanding of the impacts of different fertilizers on the structure of rhizosphere microbiome and plant and soil variables will provide fundamental information toward developing strategies for the quantity and quality of plants for sustainable agriculture.

\section{Conclusions}

Our results show the relationships between the plant and soil properties and rhizobacterial communities under different fertilizations. The addition of chemical and organic fertilizers increased the soil nutrient levels, pakchoi productivity, and reshaped bacterial community structure in the rhizosphere soil. The levels of antioxidants in pakchoi were elevated by the addition of organic fertilizer, which might be attributed to the introduced organic $\mathrm{N}$ and enriched beneficial rhizobacteria. Specifically, the OTUs from the genus Bacillus associated with organic fertilizer treatment were positively correlated to plant biomass and phenolic acid. In addition, several potential beneficial rhizobacteria positively correlated to pakchoi biomass or antioxidants were observed. Furthermore, the shifted functions of the rhizobacterial community by organic fertilizer showed positive correlations with plant antioxidant activity. We therefore speculate that the improvement of antioxidant levels under organic fertilization might be related to the changed rhizobacterial community. Further study is needed to identify the roles of organic fertilizer-sensitive bacterial taxa on the biosynthesis of antioxidants in plants. Such knowledge is particularly related to the selection and development of beneficial rhizobacteria to enhance plant productivity and quality.

Supplementary Materials: The following are available online at http://www.mdpi.com/2071-1050/11/8/2424/s1, S1: Analysis of plant antioxidants, Table S1: Chemical properties of soil and organic fertilizer used in this study, Table S2: Permutational multivariate analysis of variance (PERMANOVA) to investigate the effects of fertilization on the plant, soil and rhizobacterial community structure, Table S3: Pearson correlation among plant variables measured in this study, Table S4: Reads, number of OTUs and $\alpha$-diversity indices under different fertilizer treatments, Table S5: The 40 most abundant rhizobacteria at genus level under different fertilizations. Figure S1: 
Rarefaction curve of Miseq pyrosequencing in the rhizosphere of pakchoi under different fertilizations, Figure S2: Relative abundance of bacterial phyla in the rhizosphere of pakchoi under different fertilizations, Figure S3: Predicted functional pathways of rhizobacterial communities under different fertilizations.

Author Contributions: Conceptualization, J.L. and D.H.; Formal Analysis, J.L. and M.K.; Funding Acquisition, D.H.; Methodology, J.L., M.K. and D.H.; Project Administration, D.H.; Software, J.L. and Y.L.; Supervision, D.H.; Visualization, J.L., J.Y. and Y.L.; Writing-Original Draft, J.L.; and Writing-Review and Editing, J.Y., Y.L., M.K. and D.H.

Funding: This study was supported in part by the program of the Science and Extension of Shanghai Agriculture Committee (2017 (3-4)) and the Shanghai Modern Leaf-vegetable Industry Technology Research System (Grant No. 2019-2). Any opinions, findings, conclusions, or recommendations expressed in this publication are those of the authors and do not necessarily reflect the views of the Ministry of Science and Technology of China or Shanghai Jiao Tong University.

Acknowledgments: We thank the Shanghai Personal Biotechnology Co., Ltd., China (Shanghai, China) for their kind assistance with the pyrosequencing experiments.

Conflicts of Interest: The authors declare no conflicts of interest.

\section{References}

1. Reganold, J.P.; Wachter, J.M. Organic agriculture in the twenty-first century. Nat. Plants 2016, 2, 15221. [CrossRef] [PubMed]

2. Lehesranta, S.J.; Koistinen, K.M.; Massat, N.; Davies, H.V.; Shepherd, L.V.T.; McNicol, J.W.; Cakmak, I.; Cooper, J.; Lück, L.; Kärenlampi, S.O.; et al. Effects of agricultural production systems and their components on protein profiles of potato tubers. Proteomics 2007, 7, 597-604. [CrossRef]

3. Wojtaszek, P.; Stobiecki, M.; Gulewicz, K. Role of nitrogen and plant growth regulators in the exudation and accumulation of lsoflavonoids by roots of intact white lupin (Lupinus albus L.) plants. J. Plant Physiol. 1993, 142, 689-694. [CrossRef]

4. Kong, L.; Xie, Y.; Hu, L.; Si, J.; Wang, Z. Excessive nitrogen application dampens antioxidant capacity and grain filling in wheat as revealed by metabolic and physiological analyses. Sci. Rep. 2017, 7, 43363. [CrossRef] [PubMed]

5. Coronado, C.; Esnault, R.; Kondorosi, A.; Ratet, P. Alfalfa root flavonoid production is nitrogen regulated. Plant Physiol. 1995, 108, 533-542. [CrossRef] [PubMed]

6. Tartoura, K.A.H.; Youssef, S.A.G. Effect of compost on the antioxidant defense systems of cucumber (Cucumis satious L.) against cadmium toxicity. Ann. Agric. Sci. 2010, 191-203.

7. Yang, X.; Feng, L.; Zhao, L.; Liu, X.; Hassani, D.; Huang, D. Effect of glycine nitrogen on lettuce growth under soilless culture: A metabolomics approach to identify the main changes occurred in plant primary and secondary metabolism. J. Sci. Food Agric. 2018, 98, 467-477. [CrossRef] [PubMed]

8. Gans, J.; Wolinsky, M.; Dunbar, J. Computational improvements reveal great bacterial diversity and high metal toxicity in soil. Science 2005, 309, 1387-1390. [CrossRef]

9. Berendsen, R.L.; Pieterse, C.M.J.; Bakker, P.A.H.M. The rhizosphere microbiome and plant health. Trends Plant Sci. 2012, 17, 478-486. [CrossRef]

10. Hinsinger, P. Structure and function of the rhizosphere: Mechanisms at the soil-root interface. Ocl-Ol. Corps Gras Lipides 1998, 5, 340-341.

11. Wang, Q.; Jiang, X.; Guan, D.; Wei, D.; Zhao, B.; Ma, M.; Chen, S.; Li, L.; Cao, F.; Li, J. Long-term fertilization changes bacterial diversity and bacterial communities in the maize rhizosphere of Chinese Mollisols. Appl. Soil Ecol. 2018, 125, 88-96. [CrossRef]

12. Pineda, A.; Kaplan, I.; Bezemer, T.M. Steering soil microbiomes to suppress aboveground insect pests. Trends Plant Sci. 2017, 22, 770-778. [CrossRef] [PubMed]

13. Saharan, B.S. Plant growth promoting rhizobacteria: A critical review. Life Sci. Med. Res. 2011, 21, 30.

14. Bacon, C.W.; Palencia, E.R.; Hinton, D.M. Abiotic and Biotic Plant Stress-Tolerant and Beneficial Secondary Metabolites Produced by Endophytic Bacillus Species. In Plant Microbes Symbiosis: Applied Facets; Arora, N.K., Ed.; Springer India: Uttar Pradesh, India, 2015; pp. 163-177. ISBN 978-81-322-2068-8.

15. Singhai, P.K.; Sarma, B.K.; Srivastava, J.S. Biological management of common scab of potato through Pseudomonas species and vermicompost. Biol. Control 2011, 57, 150-157. [CrossRef] 
16. Kavamura, V.N.; Hayat, R.; Clark, I.M.; Rossmann, M.; Mendes, R.; Hirsch, P.R.; Mauchline, T.H. Inorganic nitrogen application affects both taxonomical and predicted functional structure of wheat rhizosphere bacterial communities. Front Microbiol. 2018, 9, 1074. [CrossRef]

17. Wolters, B.; Jacquiod, S.; Sørensen, S.J.; Widyasari-Mehta, A.; Bech, T.B.; Kreuzig, R.; Smalla, K. Bulk soil and maize rhizosphere resistance genes, mobile genetic elements and microbial communities are differently impacted by organic and inorganic fertilization. FEMS Microbiol. Ecol. 2018, 94, fiy027. [CrossRef] [PubMed]

18. Sharma, P.; Kumari, H.; Kumar, M.; Verma, M.; Kumari, K.; Malhotra, S.; Khurana, J.; Lal, R. From bacterial genomics to metagenomics: Concept, tools and recent advances. Indian J. Microbiol. 2008, 48, 173-194. [CrossRef]

19. Acosta-Martinez, V.; Dowd, S.; Sun, Y.; Allen, V. Tag-encoded pyrosequencing analysis of bacterial diversity in a single soil type as affected by management and land use. Soil Biol. Biochem. 2008, 40, 2762-2770. [CrossRef]

20. Langille, M.G.I.; Zaneveld, J.; Caporaso, J.G.; McDonald, D.; Knights, D.; Reyes, J.A.; Clemente, J.C.; Burkepile, D.E.; Vega Thurber, R.L.; Knight, R.; et al. Predictive functional profiling of microbial communities using 16S rRNA marker gene sequences. Nat. Biotechnol. 2013, 31, 814-821. [CrossRef]

21. Ding, J.; Zhao, L.; Wang, L.; Zhao, W.; Zhai, Z.; Leng, L.; Wang, Y.; He, C.; Zhang, Y.; Zhang, H.; et al. Divergent selection-induced obesity alters the composition and functional pathways of chicken gut microbiota. Genet. Sel. Evol. 2016, 48, 93. [CrossRef]

22. Abia, A.L.K.; Alisoltani, A.; Keshri, J.; Ubomba-Jaswa, E. Metagenomic analysis of the bacterial communities and their functional profiles in water and sediments of the Apies river, South Africa, as a function of land use. Sci. Total Environ. 2018, 616, 326-334. [CrossRef] [PubMed]

23. Bonanomi, G.; De Filippis, F.; Cesarano, G.; La Storia, A.; Ercolini, D.; Scala, F. Organic farming induces changes in soil microbiota that affect agro-ecosystem functions. Soil Biol. Biochem. 2016, 103, 327-336. [CrossRef]

24. Xiao, X.; Fan, M.; Wang, E.; Chen, W.; Wei, G. Interactions of plant growth-promoting rhizobacteria and soil factors in two leguminous plants. Appl. Microbiol. Biotechnol. 2017, 101, 8485-8497. [CrossRef] [PubMed]

25. IUSS Working Group WRB. World Reference Base for Soil Resources 2006; World Soil Resources Report; FAO: Rome, Italy, 2010.

26. Tariq Rafiq, M.; Aziz, R.; Yang, X.; Xiao, W.; Stoffella, P.J.; Saghir, A.; Azam, M.; Li, T. Phytoavailability of cadmium (Cd) to pak choi (Brassica chinensis L.) grown in chinese soils: A model to evaluate the impact of soil Cd pollution on potential dietary toxicity. PLoS ONE 2014, 9, e111461.

27. Eghball, B.; Wienhold, B.J.; Gilley, J.E.; Eigenberg, R.A. Mineralization of manure nutrients. J. Soil Water Conserv. 2002, 57, 470-473.

28. Lundberg, D.S.; Lebeis, S.L.; Paredes, S.H.; Yourstone, S.; Gehring, J.; Malfatti, S.; Tremblay, J.; Engelbrektson, A.; Kunin, V.; del Rio, T.G.; et al. Defining the core Arabidopsis thaliana root microbiome. Nature 2012, 488, 86-94. [CrossRef] [PubMed]

29. Singleton, V.L.; Orthofer, R.; Lamuela-Raventós, R.M. Analysis of total phenols and other oxidation substrates and antioxidants by means of folin-ciocalteu reagent. Methods Enzym. 1999, 299, 152-178.

30. Szaufer-Hajdrych, M. Phenolic acids in leaves of species of the Aquilegia L. genus. Herba Pol. 2004, 50, 50-54.

31. Lamaison, J.L.; Carnat, A. The amount of main flavonoids in flowers and leaves of Crataegus monogyna Jacq. and Crataegus laevigata (Poiret) DC. (Rosaceae). Pharm. Acta Helv. 1990, 65, 315-320.

32. Złotek, U.; Świeca, M.; Jakubczyk, A. Effect of abiotic elicitation on main health-promoting compounds, antioxidant activity and commercial quality of butter lettuce (Lactuca sativa L.). Food Chem. 2014, 148, $253-260$.

33. Magoč, T.; Salzberg, S.L. FLASH: Fast length adjustment of short reads to improve genome assemblies. Bioinformatics 2011, 27, 2957-2963. [CrossRef]

34. Edgar, R.C. Search and clustering orders of magnitude faster than BLAST. Bioinformatics 2010, 26, $2460-2461$. [CrossRef]

35. Khalid, M.; Hassani, D.; Bilal, M.; Huang, D. Elevation of secondary metabolites synthesis in Brassica campestris ssp. chinensis L. via exogenous inoculation of Piriformospora indica with appropriate fertilizer. PLoS ONE 2017, 12, e0177185. [CrossRef]

36. Segata, N.; Izard, J.; Waldron, L.; Gevers, D.; Miropolsky, L.; Garrett, W.S.; Huttenhower, C. Metagenomic biomarker discovery and explanation. Genome Biol. 2011, 12, R60. [CrossRef] 
37. R-Core-Team. R: A Language and Environment for Statistical Computing; R Foundation for Statistical Computing: Vienna, Austria, 2014.

38. Hammer, Ø.; Harper, D.A.T.; Ryan, P.D. Past: Paleontological statistics software package for education and data analysis. Palaeontol. Electron. 2001, 4, 1-9.

39. Ghani, A.; Dexter, M.; Carran, R.A.; Theobald, P.W. Dissolved organic nitrogen and carbon in pastoral soils: The New Zealand experience. Eur. J. Soil Sci. 2007, 58, 832-843. [CrossRef]

40. Näsholm, T.; Kielland, K.; Ganeteg, U. Uptake of organic nitrogen by plants. New Phytol. 2009, 182, 31-48. [CrossRef] [PubMed]

41. Francioli, D.; Schulz, E.; Lentendu, G.; Wubet, T.; Buscot, F.; Reitz, T. Mineral vs. organic amendments: Microbial community structure, activity and abundance of agriculturally relevant microbes are driven by long-term fertilization strategies. Front Microbiol. 2016, 7, 1446. [CrossRef]

42. Ren, G.; Ma, Y.; Guo, D.; Gentry, T.J.; Hu, P.; Pierson, E.A.; Gu, M. Soil bacterial community was changed after Brassicaceous seed meal application for suppression of Fusarium wilt on pepper. Front Microbiol. 2018, 9, 185. [CrossRef] [PubMed]

43. Tang, J.; Zheng, A.P.; Bromfield, E.S.P.; Zhu, J.; Li, S.C.; Wang, S.Q.; Deng, Q.M.; Li, P. 16S rRNA gene sequence analysis of halophilic and halotolerant bacteria isolated from a hypersaline pond in Sichuan, China. Ann. Microbiol. 2011, 61, 375-381. [CrossRef]

44. Pershina, E.V.; Ivanova, E.A.; Nagieva, A.G.; Zhiengaliev, A.T.; Chirak, E.L.; Andronov, E.E.; Sergaliev, N.K. A comparative analysis of microbiomes in natural and anthropogenically disturbed soils of northwestern Kazakhstan. Eurasian Soil Sci. 2016, 49, 673-684. [CrossRef]

45. Andersson, A.; Höglander, H.; Karlsson, C.; Huseby, S. Key role of phosphorus and nitrogen in regulating cyanobacterial community composition in the northern Baltic Sea. Estuar. Coast. Shelf Sci. 2015, 164, 161-171. [CrossRef]

46. Chokshi, K.; Pancha, I.; Ghosh, A.; Mishra, S. Nitrogen starvation-induced cellular crosstalk of ROS-scavenging antioxidants and phytohormone enhanced the biofuel potential of green microalga. Biotechnol. Biofuels 2017, 10, 60. [CrossRef]

47. Kaewkla, O.; Franco, C.M.M. Rational approaches to improving the isolation of endophytic actinobacteria from Australian native trees. Microb. Ecol. 2013, 65, 384-393. [CrossRef] [PubMed]

48. Ye, J.; Zhang, R.; Nielsen, S.; Joseph, S.D.; Huang, D.; Thomas, T. A combination of biochar-mineral complexes and compost improves soil bacterial processes, soil quality, and plant properties. Front Microbiol. 2016, 7, 372. [CrossRef] [PubMed]

49. Ye, J.; Perez, P.G.; Zhang, R.; Nielsen, S.; Huang, D.; Thomas, T. Effects of different C/N ratios on bacterial compositions and processes in an organically managed soil. Biol. Fert. Soils 2017, 54, 137-147. [CrossRef]

50. Gong, W.; Yan, X.; Wang, J. The effect of chemical fertilizer on soil organic carbon renewal and $\mathrm{CO}_{2}$ emission-A pot experiment with maize. Plant Soil 2011, 353, 85-94. [CrossRef]

51. Bacon, C.W.; White, J.F., Jr. Functions, mechanisms and regulation of endophytic and epiphytic microbial communities of plants. Symbiosis 2016, 68, 87-98. [CrossRef]

52. Gu, Y.; Wang, Y.; Lu, S.; Xiang, Q.; Yu, X.; Zhao, K.; Zou, L.; Chen, Q.; Tu, S.; Zhang, X. Long-term fertilization structures bacterial and archaeal communities along soil depth gradient in a paddy soil. Front Microbiol. 2017, 8, 1516. [CrossRef] [PubMed]

53. Gluszek, S.; Sas-Paszt, L.; Sumorok, B.; Kozera, R. Biochar-Rhizosphere interactions-A review. Pol. J. Microbiol. 2017, 66, 151-161. [CrossRef] [PubMed]

54. Ikoyi, I.; Fowler, A.; Schmalenberger, A. One-time phosphate fertilizer application to grassland columns modifies the soil microbiota and limits its role in ecosystem services. Sci. Total Environ. 2018, 630, 849-858. [CrossRef] [PubMed] 
55. Xu, L.; Yi, M.; Yi, H.; Guo, E.; Zhang, A. Manure and mineral fertilization change enzyme activity and bacterial community in millet rhizosphere soils. World J. Microbiol. Biotechnol. 2018, 34, 8. [CrossRef] [PubMed]

56. Ding, L.; Su, J.; Sun, G.; Wu, J.; Wei, W. Increased microbial functional diversity under long-term organic and integrated fertilization in a paddy soil. Appl. Microbiol. Biotechnol. 2018, 102, 1969-1982. [CrossRef] [PubMed]

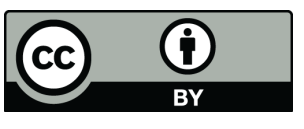

(C) 2019 by the authors. Licensee MDPI, Basel, Switzerland. This article is an open access article distributed under the terms and conditions of the Creative Commons Attribution (CC BY) license (http://creativecommons.org/licenses/by/4.0/). 